\title{
¿Hay un lugar en Rawls para la cuestión ambiental?
}

\author{
JOAQUÍN VALDIVIELSO \\ Universidad de las Islas Baleares
}

Resumen. Pueden identificarse cuatro estrategias principales de tratar la cuestión ambiental de acuerdo al marco rawlsiano. Extender la posición original o el principio de igualdad de oportunidades afecta a la concepción de la justicia. Reconocer límites naturales o ambientales a nivel de esencia constitucional o abrir la fase legislativa a la justicia ambiental afectan al liberalismo político. En cualquiera de ellas, el esquema sólo permitiría ir más lejos cuestionando la visión nacional-estatal de sociedad cooperativa.

Obviamente, Rawls no fue un filósofo ambiental. Ni siquiera se interesó por la justicia ambiental o por el llamado liberalismo verde. No obstante, hay al menos dos buenas razones para preguntarse qué puede aportarnos su obra al respecto. $\mathrm{La}$ primera tiene que ver con el peso que ha ganado como un marco general desde el cual evaluar y discutir no sólo sobre la justicia y el liberalismo, sino sobre filosofía política contemporánea en general. Dado que la cuestión ambiental es sin duda un problema contemporáneo -incluso clave- en el cual cristalizan algunos de los retos más importantes actuales para la filo-
ABSTRACT. Four main strategies can be identified in dealing with environmental issues within the Rawlsian framework. Two concern the concept of justice: extending the original position and enriching the principle of equal opportunity. And two concern political liberalism: recognizing environmental or natural constraints at the level of constitutional essentials and opening the democratic process to environmental justice. In any of them, Rawls' proposal is flawed because of its nationstate view of a cooperative society.

sofía, puede ser interesante probar la «resiliencia» de la propuesta rawlsiana desde esa perspectiva. La segunda razón es que la obra de Rawls, y en particular sus principios de justicia, es omnipresente - también - en los trabajos que desde la economía, la geografía, el derecho o la ciencia política tocan la cuestión ambiental.

Han sido y son numerosas las vías por las cuales se ha probado el cruce entre medio ambiente y filosofía rawlsiana. Pueden ordenarse siguiendo el itinerario general descrito por Rawls y sus grandes hitos, en el sentido de que algunas son intentos específicos de reivindicar o al menos ajus- 
tar el marco que supuso Una Teoría de la Justicia, mientras que otras más recientes apuntan a El liberalismo político ${ }^{1}$. En general, en todas ellas suele asumirse - con cierta ligereza - más continuidades que rupturas.

\section{Principios de justicia y bienes ambientales}

Como es sabido, Rawls se propuso definir la forma ideal de la estructura básica de la sociedad. Gracias a un acuerdo o contrato hipotético - una «posición original» de imparcialidad-, partes ignorantes de sus propias creencias y circunstancias particulares - tras el «velo de ignorancia»llegarían a ciertos principios básicos de justicia, producto racional del desconocimiento de los planes de vida y características de cada uno. Las estrategias a que nos vamos a referir han incidido sobre todo en los requisitos de la posición original y el llamado problema del extensionismo, aunque antes hay que establecer qué principio debiera cubrir los bienes ambientales.

La primera formulación de los principios rawlsianos habla de dos principios, ordenados lexicográficamente. El primero postula libertades iguales básicas e irrenunciables. El segundo, que las desigualdades sociales y económicas cumplan dos requisitos: a) que beneficien a todos, $\mathrm{y}$ b) que sean fruto de posiciones sociales abiertas. Las sucesivas formulaciones del propio Rawls han tendido a separar el segundo principio en dos distintos, de manera que al final tendríamos tres: 1) libertades iguales; 2) igualdad real de oportunidades, y 3) principio de diferencia.

Los bienes primarios afectados por el primer principio son derechos y libertades fundamentales y los otros dos afectan a poderes, prerrogativas sobre autoridad, ingreso, riqueza y autoestima. Todos ellos son definidos como medios para cualquier plan de vida que los ciudadanos se plan- teen. Los bienes cubiertos por el primer principio deberían ser distribuidos de manera equitativa y en el mayor grado posible. Rawls, que piensa en bienes intangibles del tipo de las libertades políticas, consideró, pues, que los recursos naturales no tenían por qué ser distribuidos en régimen de igualdad. De hecho, los intentos de incluirlos en la lista han concluido que ésta se hacía muy poco operativa, y han invitado a pensar en vías indirectas para asegurar un entorno ambiental igual que cumpla con ciertos mínimos de calidad. Una estrategia más sólida, pues, debe partir de otro principio.

Es evidente que la salud guarda una relación directa con poder disfrutar de un medio ambiente sano, y que no disponer del mismo disminuye la igualdad de oportunidades. Dado que la salud es de un lado condición necesaria de la igualdad de oportunidades, y que a su vez es función de un conjunto de variables entre las cuales la calidad ambiental se encuentra, ésta debería quedar asegurada para todo ciudadano ${ }^{2}$. Habría que proteger, en este caso, el «capital natural crítico» para el ser humano, el imprescindible para su sano mantenimiento y reproducción. Sabemos que los efectos del cambio ambiental sobre la salud pueden ser dispersos y su aparición retardarse por generaciones, por lo que aplicar estrictamente este criterio supondría sancionar el principio de precaución. Otra ventaja que posee esta vía es que no precisa suponer la apropiabilidad de bienes y servicios ambientales comunes - como el clima o la calidad del aire o las aguas-.

Aquellos bienes que no sean imprescindibles para el goce de la salud caerían bajo el principio de diferencia. Aunque los comentaristas tienden a señalar que la distribución socioeconómica desigual sólo se justifica si produce beneficios «para todos», de acuerdo a la primera formulación de Teoría, Rawls restringió progresivamente su condicionalidad a «la mayor expectativa de beneficio para los menos 
aventajados». Afortunadamente, hay formas realmente ilustrativas de calcular cómo se distribuyen entre una población dada los bienes naturales, en cierto modo, consumibles. Es decir, los «recursos naturales». La «huella ecológica», por ejemplo, traduce todos los impactos derivados del consumo de productos y servicios ambientales en que se sostienen todas nuestras actividades diarias - mercantilizadas o no- a una única unidad, hectáreas ${ }^{3}$. Aunque suele utilizarse más para medir las huellas de economías nacionales, de ciudades, e incluso de generaciones, esta metodología permite comparar también el consumo que un individuo o grupo realiza a lo largo del tiempo. Como es previsible, demuestra que los estilos de vida más consumistas se soportan en huellas ecológicas mayores. De acuerdo al principio de diferencia, el peor situado en este caso, el que tenga menor huella, debería ser compensando, bien aumentando su huella, bien aumentando el consumo de otros bienes socioeconómicos.

Aquí se multiplican los problemas. Muchas de las propiedades de los bienes naturales son irreproducibles. Incluso los no renovables son técnicamente irreemplazables, y por lo tanto su sustitución por otros como el dinero es necesariamente arbitraria. Reducir los bienes primarios socioeconómicos a renta implica de alguna manera asumir la sustituibilidad, en nuestro caso, entre capital natural y otras formas de capital, como el financiero o el manufacturado. El hacerlo presupone, quizás inconscientemente, no sólo un optimismo tecnológico injustificado, sino también que los intereses de las generaciones venideras pesan en función de la riqueza que les presupone el presente, y a la parte de su patrimonio natural que por tanto puede descontárseles. Esta asunción «prometeica» y productivista, ejemplarmente representada por Wilfred Beckerman o por el famoso «ecologista escéptico» Bjørn Lomborg, lleva a posiciones muy controverti- das para lo que nos ocupa: 1) a denostar la existencia de límites físicos al crecimiento económico; 2) a minimizar la responsabilidad para con el futuro y los pobres en general, y 3) a reducir la agenda política a mejorar la calidad de la justicia y la libertad hoy y no «el número de especies de escarabajos o las reservas de cobre», como señala irónicamente Beckerman ${ }^{4}$.

Cuanto más amplia sea la noción de naturaleza crítica y más restringida la de recurso natural, más nos alejaríamos de la posición productivista. Así, el abanico de bienes socioeconómicos con «huella ecológica», las actividades materialmente densas, debería ser restringido y accesible de acuerdo a la igualdad de oportunidades. En caso contrario, tanto más sería el principio de diferencia una coartada ideológica al crecimiento ilimitado, dado que de él depende la mejora absoluta de los que están peor, como denuncia Ted Benton ${ }^{5}$. No obstante, no es fácil acusar a Rawls de productivista, a pesar de cierta contradicción en sus planteamientos. De un lado, insistió en que ni el principio de diferencia ni su ideal de sociedad requieren la maximización del producto social. Cabría pensar, por tanto, que la mejora del peor situado pasaría por transferencias netas de bienes; en nuestro caso, ambientales. Sin embargo, considerando qué políticas podrían aliviar a los peor situados, Rawls señaló que bastaba con «ajustar las desgravaciones fiscales» sin considerar otras decisiones políticas ${ }^{6}$. Como hemos visto, este paso sólo sería lícito si fuese acompañado de un principio de igualdad de oportunidades ambicioso y constricciones revolucionarias en los recursos naturales que pueden ser mercantilizados y monetarizados.

\section{El extensionismo}

Una vez entre los principios de justicia, queda por ver aún sobre quién tendría validez la justicia en su dimensión ambiental. Sabemos que el velo de ignorancia 
oculta accidentes y contingencias de la vida como edad, género, raza, clase o dotación natural. Las partes apenas tienen una teoría «débil» del bien: saben de las verdades generales de la historia y la política, de su apetencia por bienes primarios y de su falta de envidia, además de las circunstancias de la justicia - básicamente de la escasez moderada-. Este esquema ha planteado al menos tres tipos de críticas diferentes, todas relativas a las dificultades para «extenderlo» a tres colectivos.

La primera se remonta a autores clásicos como Peter Singer y denuncia la exclusión de los animales sintientes de la posición original ${ }^{7}$. La respuesta obvia sería que las partes deben satisfacer criterios de moralidad y racionalidad - propiamente humanos - para poder elegir su concepción de la justicia. Además, Rawls, como Brian Barry y otros liberales, acepta que los animales merecen cierta consideración dentro de una concepción moral amplia, que definiría formas de actuar correctas e incorrectas hacia ellos como «pacientes» morales, aunque no podría decirse que fueran víctimas de injusticia ${ }^{8}$. Aun así, esto no deja de ser problemático.

En primer lugar, si la concepción estrecha de la justicia forma parte de una concepción moral de mayor alcance, ¿cuál es su fundamento? Más aún, ¿no debería ser el trato a los animales un test de plausibilidad de la propia teoría de la justicia respecto a la concepción moral general? ¿Por qué no ponernos en la piel de un chimpancé siendo viviseccionado, como propone Benton? Es decir, extender el velo a lo «interespecífico» podría hacernos considerar ciertas restricciones a los principios de justicia y que la estructura social básica debería proteger ciertos bienes - como la libertad frente a la tortura- para los animales no humanos. En este caso, «espesar» el velo conllevaría poner a la naturaleza en esa especie de «estado natural de la conciencia» que es la posición original 9 . Al respecto, Andrew
Dobson, Jorge Riechmann o liberales como Marcel Wissenburg defienden que los animales son recipientes de justicia distributiva.

La segunda duda es ya un clásico de la teoría moral y se nutre del argumento de los casos marginales. Discapacitados mentales o niños quedarían, estrictamente, fuera de la posición original. Se podría aducir, al menos para los niños y como ha hecho Rawls, que éstos son seres racionales en potencia. No obstante, también se le puede dar la vuelta al argumento, como hace Garner, y pensar que todo adulto es un discapacitado mental en potencia, y en consecuencia descartar el criterio de la racionalidad ${ }^{10}$. Garner añade, además, que no hacerlo vulnera el principio de neutralidad, puesto que al excluirlos quedan reducidos a recursos de las partes en la posición original. Aunque no está claro que Rawls haga esto último - como veremos después - sí es cierto que los defensores del bienestar de los animales dan buenos motivos para pensar que la racionalidad es también una ventaja natural no merecida que debería, por tanto, ser oculta tras el velo. El problema es que, puestos así, también es arbitrario el ser o no sintiente, e incluso el ser un ser vivo y no uno inanimado. Asumir una antropología sensocéntrica no es filosóficamente menos controvertido que el velo rawlsiano, y además es también muy excluyente: la mayoría de especies conocidas, paisajes, ecosistemas enteros, quedarían fuera.

La perspectiva extensionista animal, de todas formas, se enfrenta a otro reto. $\mathrm{Si}$ los animales participasen de la posición original deberían aplicárseles principios de justicia. En este caso, se corre el peligro de caer en la utilidad máxima agregada o bien de tener que establecer algún tipo de jerarquía entre especies, y dentro de éstas, entre los peor situados y el resto. Lo más sorprendente, no obstante, es que la mayoría de los países democráticos poseen normativas que regulan el tratamiento a los 
animales y prohíben el sufrimiento innecesario. Esto es importante en la medida en que la posición original es una herramienta de representación de nuestras intuiciones. Es a través de un proceso constante de ajuste o «equilibrio reflexivo»-por el que las partes van y vienen de los principios abstractos a las intuiciones morales de los ciudadanos en la vida diariacomo la teoría aspira a reflejar los valores dominantes. Rawls podría aducir que eso se sigue de la concepción moral y que además no afecta a la estructura básica. Sin embargo, hay normativas de alto rango, estructurales, incluyendo el Tratado constitucional europeo (art. II-121), que reflejan esa sensibilidad moral ${ }^{11}$. Luego la teoría fallaría al menos en sociedades mayoritariamente concienciadas, o mejor dicho, la teoría está pensada para sociedades liberales poco concienciadas al respecto. En cualquier caso, los problemas de extensión no se acaban aquí.

Brian Barry ha señalado que imaginar un «arca de Noé» tras el velo de ignorancia permitiría proteger el hábitat a todos los seres sintientes, con lo que se protegerían el entorno ambiental en general y así los intereses de las generaciones venideras ${ }^{12}$. Como se sabe, Rawls fue en un principio reacio a poner tras el velo de ignorancia la cuestión generacional, aunque con el tiempo atendió a sus críticos dándole más peso y claridad al llamado «principio de ahorro justo». Básicamente, éste busca impedir la dilapidación del patrimonio común por parte de una generación. El principal problema tenía que ver con la importancia de la racionalidad de tipo instrumental de la Teoria de la Justicia. Como señaló Barry, el nivel de escasez es función de lo que hayan hecho las generaciones previas, $y$ eso, cuando una generación deja un entorno ambiental peor a sus descendientes que el que ella disfrutó, implica que las instituciones de la segunda no serán justas, y por lo tanto ellos no tendrían ninguna obligación para respetar el principio de ahorro justo. Rawls entrevió esta tensión para con la doctrina de las circunstancias de la justicia e incluyó una «cláusula motivacional», por la que hacía depender la justicia de sentimientos reales de preocupación. Aunque así saltaba sobre su propio método, sin duda se dio cuenta de que si la justicia equivale a la ventaja mutua, entonces no puede haber justicia entre generaciones.

Más tarde acabó definiendo el «ahorro justo» como una cláusula del principio de diferencia, por el que cada generación ahorrará capital según un patrón que desearía que toda generación, independientemente de su distancia en el tiempo, hubiera seguido, aun cuando no fuera el caso. Capital en un sentido amplio, incluyendo el natural. De este modo, ninguna generación tendría el derecho a consumir bienes ambientales que quisiera que la generación anterior le hubiera dejado. Ésta es una vía por la que todo valor natural no sólo crítico sino también irreemplazable, «irreversible», queda cubierto. Sería el mecanismo por el cual el principio de igualdad de oportunidades se hace operativo entre generaciones. De acuerdo a las premisas de partida, cabe concluir que el valor a mantener intergeneracionalmente debería ser per capita, independientemente del tamaño de la población ${ }^{13}$. Es decir, podríamos entender el principio de ahorro como la garantía a una huella ecológica más o menos igual para cualquier sujeto de cualquier generación. En este caso, a mayor población, mayor responsabilidad por mantener el patrimonio natural.

Los comentaristas suelen coincidir en señalar la radicalidad de dar el paso hacia la justicia intergeneracional, pero más aún en lo ambiental. Hay que recordar que los cambios ambientales no pasan linealmente de una generación a otra, pueden ser bienes para la generación siguiente, y males para alguna posterior, o al revés. Esto obliga a acentuar la dimensión de universabilidad y el compromiso con el principio de 
precaución. Sin embargo, ya desde su Teoría Rawls incidió en que el velo de ignorancia se aplicaba a contemporáneos en una sociedad única, básicamente conciudadanos de un Estado - aunque desconozcan a qué generación pertenecen-. Este criterio se ha acentuado en el tránsito hacia la concepción política de El liberalismo politico, y ha culminado en El derecho de gentes, cerrando tajantemente las puertas a la ignorancia intrageneracional. Resultado de ello es la clausura de un tratamiento adecuado a la cuestión ambiental.

\section{Nacionalismo metodológico y justicia ambiental}

Las partes saben, pues, que son miembros libres e iguales de una sociedad bien ordenada, de un pueblo. Como tal, está políticamente organizado en una unidad territorial bajo un régimen de democracia constitucional que supone el ejercicio legítimo del poder y la inclusión en instituciones en que se entra al nacer y se está de por vida. Además, tiene carácter moral, posee una solidaridad motivacional que le distingue del «otro», aunque eso no supone que actúe de manera «realista» o hobbesiana para con otros Estados o pueblos, que esté animado por el deseo de poder, de recursos económicos o de expansión territorial. Estos pueblos liberales, pues, no lidian racionalmente sino razonablemente con otros en la arena internacional; otros que sin ser liberales son decentes $-\mathrm{y}$ con los que por tanto se pueden establecer principios de justicia-; y otros «agresivos y peligrosos», dispuestos a promover la guerra si sirve a sus intereses racionales. Ejemplos de estos últimos serían las imperialistas España y Francia, y más recientemente Alemania. Llama la atención que Rawls no cite a Inglaterra, contra la cual se constituyeron los Estados Unidos de América. Su modelo cae, obviamente, dentro de lo que Ulrich Beck llama «nacionalismo metodo- lógico», la división de la humanidad en un número limitado de naciones con fronteras organizativas claras que separan el «dentro» del «fuera» ${ }^{14}$.

El hecho de que los pueblos, y no los individuos, sean los actores internacionales y que la razonabilidad esté restringida a los liberales, conduce forzosamente a un escenario distinto al de Teoría, aunque Rawls hable de una «segunda posición original» para referirse a una sociedad de naciones como escenario razonable para las relaciones internacionales. La crítica cosmopolita ha lamentado, por ejemplo, que el compromiso con la justicia se pierda en la arena internacional y quede subsumido a, entre otros, un principio caritativo de asistencia ${ }^{15}$. Rawls aduciría que eso es inviable y que no hay consenso para ello, sin embargo críticos como Allen Buchanan le acusan de no querer ir más allá de un Derecho internacional ya vigente, y de no reconocer que ya existen instituciones globales y regímenes de gobernanza que limitan de largo la soberanía de los pueblos, donde podrían aplicarse la igualdad de oportunidades, la participación democrática en las instituciones y la justicia distributiva. Más aún, cabe preguntarse qué ciudadanía habita un territorio definido a lo largo de generaciones sin que su pueblo sufra cambios estructurales de tipo político y sin que los propios límites del pueblo se redefinan: la mayoría de las que conocemos, no.

Para lo que aquí se trata, destaca el hecho de que Rawls considera que estas sociedades domésticas son responsables del bienestar de sus pueblos, que son unidades económicas autosuficientes distributivamente y que, por lo tanto, pueden cubrir autónomamente las necesidades materiales de sus poblaciones. Los cosmopolitas destacan que ya existe una estructura básica global - formada por acuerdos económicos, regímenes financieros, un sistema global de derechos de propiedad privada, etc. - que promueve una distri- 
bución tremendamente desigual de los bienes primarios, especialmente los económicos, entre individuos y pueblos, y que por tanto cabe exigir lo mismo que se exige al nivel intergeneracional o intrasocietal. Hay que recordar que si las instituciones de fondo no son justas, los acuerdos tampoco lo serán.

Con la mirada puesta en lo económico, el cosmopolitismo subraya además la superación de dos prejuicios propios de la concepción tipo Westfalia a la que se adhiere Rawls. Beitz, por ejemplo, señala que en lo económico -incluyendo los recursos naturales - no hay manera de distinguir entre influencias domésticas e internacionales en la condición económica de una sociedad. Wenar, por su parte, añade que dada la inmensa expansión del producto mundial, el razonamiento tipo «suma cero» es «obviamente inapropiado»: ya no es el caso que si unos avanzan, otros retroceden; que si unos tienen más, otros menos. Descartar ambas asunciones - el encadenamiento de la sociedad a lo nacional, la economía internacional como un juego de saldo cero- haría posible reconocer la responsabilidad de los ricos en la situación de los pobres, así como establecer acuerdos para transferencias no excesivamente gravosas de unos a otros.

Ecológicamente, no obstante, no habría que descartar esas ideas. Como muestra la huella ecológica, el patrimonio natural es más o menos fijo. De hecho, el consumo ambiental de los ricos es causa directa del infraconsumo de los pobres o de los que están por nacer. La ecología global es un juego de suma cero. Si, además, echamos las cuentas entre generaciones, veremos que la generación actual está en números rojos, puesto que está dilapidando el patrimonio futuro $-\mathrm{e}$ incumpliendo el principio de ahorro-. En segundo lugar, y aunque la ambiental es la cuestión «cosmopolita» - global- por definición, el desencadenamiento entre sociedad y nación no debería confundirse con la indefinición. Las huellas ecológicas son eso, huellas, rastros distinguibles que dejan los individuos, grupos y sociedades resultado de su forma de consumir y producir.

Así, por ejemplo, puede decirse que la huella ecológica de un norteamericano o un holandés medio, tipo, multiplica por diez la huella media de un habitante de un país pobre. La huella ecológica absoluta de Estados Unidos es una cuarta parte de la de toda la humanidad, teniendo apenas un 5 por 100 de la población mundial. Las huellas son necesariamente transnacionales. No sólo por la dispersión global de las formas de contaminación o por el consumo de bienes comunes globales, como el clima, sino también porque los recursos fluyen hacia los colectivos que los controlan recorriendo el planeta. Pero éstos, los sobreconsumidores, pueden ser identificados. Considerar a la vez la dimensión intra e intergeneracional de la distribución de los bienes ambientales arrojaría un juicio condenatorio desde la concepción de la justicia para pueblos como los Estados Unidos, beneficiarios de un orden global a todas luces injusto. Quienes utilizan los principios de justicia en las ciencias sociales tienden de hecho a interpretarlos así, como principios virtualmente universales.

La respuesta al por qué Rawls no lo hace hay que buscarla en el énfasis de la segunda parte de su propuesta, en su concepción política, en la concreción de las partes contratantes, y la definición de la libertad y la igualdad como productos de la cultura política dominante.

\section{Antropocentrismo comprehensivo y concepción política}

Durante los años noventa Rawls desplazó sus preocupaciones desde la problemática de la distribución hacia la de la estabilidad en sociedades plurales. El problema ahora es cómo preservar el desencanto postmetafísico de la modernidad compleja y a la 
vez solventar el fundamento normativo de la convivencia de doctrinas religiosas y filosóficas eventualmente enfrentadas. Para ello extiende una red conceptual relativamente nueva, alimentada, no obstante, con el espíritu tolerante del liberalismo de la Reforma, y que a grandes rasgos pretende desplegar y modular las intuiciones subyacentes a la cultura política de sociedades democráticas.

En sus términos, una sociedad de este tipo descansa en un consenso normativo implícito sobre el que pivotan y se entrecruzan doctrinas comprehensivas religiosas, morales y filosóficas razonables. Así, la concepción política de consenso se presenta como un punto de vista independiente de compromisos ontológicos, morales o epistemológicos, a los que no debe razonablemente apelarse en su contenido básico: las esencias constitucionales y las cuestiones de justicia básica. La noción de razonabilidad define el criterio de plausibilidad — que no de verdad-, así como el ámbito público de dominio de valores políticos - no metafísicos-. Sus sujetos son ciudadanos que han interiorizado el deber de civilidad y que disfrutan de libertad, igualdad y de la capacidad moral de sostener y revisar su propia idea del bien así como de desarrollar un sentido de la justicia. El resultado es el de una sociedad bien ordenada, expresión de las actividades cooperativas de sus miembros libres, iguales y razonables.

Aceptado este marco, dos vías principales pueden ser tanteadas para pensar la cuestión ambiental. La primera la piensa como parte de la concepción política, la segunda, como doctrina comprehensiva razonable.

El principal problema con que nos encontramos es el de encajar políticas ambientales en un estado liberal neutral. Al respecto, los argumentos de la razón pública deben contribuir a la cooperación. Como el propio Rawls contempla en Liberalismo político, hay «valores políticos» no comprehensivos que permiten algún tipo de protección ambiental. En particular, la preservación de lo que podríamos definir como: 1) la capacidad de mantenimiento de la vida; 2) la biodiversidad, y $3)$ los valores recreativos y científicos ${ }^{16}$. En todo caso se trata de «promover nuestro propio bien y el de las generaciones venideras», y por lo tanto adoptamos una perspectiva antropocéntrica. Ajustada a la razón pública, puesto que contribuir y participar en una sociedad cooperativa como miembro pleno pasa por disfrutar de una salud y expectativas de vida en igualdad de condiciones y de oportunidades. Es decir, satisfaciendo los criterios del segundo principio y evitando acentuar la escasez moderada propia de las circunstancias de la justicia. Como recuerda Derek Bell la neutralidad no implica inacción, simplemente razonabilidad.

Bell sostiene además que los valores «sostenibilidad» y «biodiversidad» satisfacen los requisitos, pero que el tercer caso es controvertido: "el goce de una comprensión más profunda del mundo» y de «las bellezas de la naturaleza» es un valor ajeno a la razón pública. Según su opinión, los dos primeros ratifican el principio de igualdad de oportunidades. Si la idea de ciudadano presupone una distribución justa de costes y beneficios resultantes de la cooperación social, los costes y beneficios de la transformación de la naturaleza deberían ser objeto de justicia, en este caso justicia ambiental. Sin embargo, como ya hemos indicado antes, la distribución justa estaría sujeta a los principios de ahorro y diferencia respecto de la naturaleza como capital natural crítico y como recurso natural, en cualquier caso como «proveedor de necesidades básicas humanas» o «medio de existencia».

Estas dos acepciones quedan cubiertas por el término sostenibilidad -mantenimiento del capital natural-, pero no la de biodiversidad. Buena parte de las especies vivas probablemente no tengan ninguna 
utilidad como recurso para el ser humano, incluso una parte - menor, sin dudapuede no ser imprescindible para el mantenimiento de los ciclos de materiales y energía que hacen posible la vida humana. En este caso, las constricciones de la razón pública tampoco incluirían, por ejemplo, la protección de espacios naturales o paisajes, en contra de la idea de Bell. Probablemente Rawls, en su ejemplo, no se ciñe a los propios requisitos de la razón pública.

Este estrechamiento de la razón tiene, no obstante, dos salidas posibles. La de más peso entre los liberales recuerda que es preciso preservar aquellos bienes necesarios para ciertas formas de vida que los futuros ciudadanos podrían querer perseguir. No es justo limitarse a la posibilidad de mirar la naturaleza simplemente como un bien a explotar de forma utilitarista por los seres humanos. Desde una posición antropocéntrica - pero no utilitaristapuede concebirse una perspectiva de respeto para el medio ambiente independientemente de la concepción que se tenga del mismo. Es decir, que la ambiental es una cuestión sobre la que puede existir controversia puesto que la concepción dominante -y mayormente liberal - del medio ambiente como recurso susceptible de ser apropiado es controvertida en sí misma. Las partes en la posición original, como defienden Brian Barry o Andrew Dobson, no tendrían por qué reducir a «recurso» cualquier entidad excluida de la posición 17.

Simon Hailwood abre una interesante y sorprendente vía alternativa ${ }^{18}$. Hay motivos de peso - sostiene - para pensar que existe una naturaleza no humana independiente, una historia natural que no es reductible a la naturaleza humana ni a los híbridos naturaleza-cultura, como son el medio ambiente o el paisaje en general. Esta «visión de la otredad» (the otherness view) refiere a procesos naturales autónomos que subyacen tras las formas concretas en que lo cultural y lo natural se fun- den, y a sus leyes como intentan ser captadas por la ciencia natural. Por supuesto ésta es una perspectiva controvertida, y de hecho ha sido negada por pensadores como Ulrich Beck, Anthony Giddens o Bruno Latour, pero Hailwood insiste: no es parte de ninguna visión comprehensiva, no determina una forma de vida particular ni resulta de aplicar los criterios de razonabilidad - las cargas del juicio-. Es precisamente lo contrario: excluir esta posibilidad de los temas de la razón pública supone asumir una visión puramente instrumental de la naturaleza, derivada de una doctrina comprehensiva: el antropocentrismo. Habíamos quedado que la arena política no debe identificarse con ninguna doctrina comprehensiva o con preferencias o intereses no-públicos.

La visión de lo otro no lleva necesariamente a un reencantamiento de la naturaleza, ni siquiera la extensión de la comunidad moral, pero invita a suspender la identificación de la naturaleza con un paisaje, del tipo que sea, o con un depositario de recursos. Continúa centrada en lo humano, no implica imposibles retornos a la naturaleza prístina, pero denuncia el prejuicio comprehensivo antropocéntrico que sostiene la identificación de la naturaleza con su construcción y uso socioeconómicos. La exclusión de este «imperialismo comprehensivo» reforzaría la neutralidad liberal, pero la lleva un paso más lejos: neutral no sólo respecto a la concepción del medio ambiente, sino incluso respecto a la de naturaleza. Así, no coincide con la propuesta anterior de respeto a los planes de vida posible, pero la complementa.

El gran problema es cómo se traduce esta propuesta en la práctica política y si forma parte de la cultura política democrática. La respuesta a lo segundo es evidentemente negativa. Por lo tanto, las convicciones que alimentan el equilibrio reflexivo tienen ciertos fundamentos ontológicos - antropocéntricos-, y entran en 
contradicción con la concepción política de Rawls ${ }^{19}$. Respecto a lo primero, Hailwood señala que el respeto por la naturaleza qua «lo otro» podría figurar como un «requisito político externo», algo en que coincidiría la primera vía, la de respeto por los planes de vida posibles. En su debe, ambas conllevan el peligro de inacción. La preservación de las condiciones de posibilidad de cualquier vida futura, sin mayores matices, impide cualquier transformación del entorno natural por pequeña que fuera. Por su parte, la presencia de «lo otro» natural se da incluso en los ambientes más antropizados, la vida continúa incluso en entornos muy hostiles. En su haber, fuerzan la concepción rawlsiana en una dirección ambientalmente más inclusiva.

En primer lugar, esto conllevaría sin duda una redefinición al menos parcial de la cualidad «libertad» del sujeto político, cuyo margen de acción estaría restringido por una mayor dosis de autocontención respecto a la naturaleza no-humana. Por ejemplo: restringir la posibilidad de perseguir el ideal comprehensivo «la naturaleza es un recurso natural» a través de acciones privadas ajenas a la razón pública, como consumir espacio ecológico a través de los bienes primarios de bienestar y renta. Ahora bien, los frenos al consumismo comprehensivo sólo abarcarían el entorno natural del pueblo o Estado de referencia. La vía de respeto por los planes de vida futuros limitaría sólo aquellas actividades que afecten a los conciudadanos, pero en toda aquella actividad cuyos costes ambientales pudieran ser externalizados hacia «el otro» - como muestra la huella ecológica- no habría en principio motivo de injusticia. Desgraciadamente, como ya hemos indicado, la naturaleza no respeta las fronteras políticas de los pueblos o Estados, por lo que el ciudadano razonable futuro podría tener que cargar con los costes de actividades ajenas a nuestros antecesores conciudadanos. Pensemos en el cambio climático, cuya lista de responsa- bles encabeza Estados Unidos y cuyos costes sociales y humanos, aun cuando van a parar sobre todo a países pobres, también les afectan. Estrictamente hablando, pues, el ciudadano liberal sería ambientalmente razonable en términos globales sólo tras un cálculo racional, no razonable, de probabilidades de los efectos del cambio ambiental sobre cada sociedad, incluida la suya.

No hay que olvidar que para Rawls el florecimiento de la sociedad doméstica es el valor político último, valor que opone explícitamente al objetivo cosmopolita del «bienestar de los individuos». En este caso, y dado que Rawls ha definido la sociedad en términos de autosuficiencia, se hace abstracción de la capacidad de un pueblo para limitar las oportunidades de acceder a medios de uso universal, económicos y ecológicos, por parte de otros. Así, el hecho distintivo nacional que sostiene su idea de pueblo - plural dentro de una unidad moral y política incuestionable - se convierte en una patente de corso para sociedades sobreconsumidoras de espacio ambiental global. Rawls cae así de pleno en los prejuicios productivistas antes citados: infravalora a los pobres no nacionales como víctimas de injusticia distributiva y sobrevalora la calidad política interna de las instituciones:

el elemento determinante de la suerte de un país es su cultura política - las virtudes cívicas de sus ciudadanos y políticas de sus miembros- y no el nivel de sus recursos, la arbitrariedad en la distribución de los recursos naturales no genera dificultad ${ }^{20}$.

Desde el punto de vista ambiental esto es una forma de «nacionalismo normativo». De hecho, la idea de pueblo cobra supremacía sobre los principios de la justicia gracias a que se enmascaran los mecanismos no-públicos que permiten perseguir ideales comprehensivos en la aldea global. Algunos de estos ideales, como el american way of life, incluso refuerzan el 
hecho distintivo nacional de partida, que se supone neutral en el corazón del consenso. Al pensar el pluralismo en estos términos, Rawls no le ve más amenaza que el uso opresivo del poder estatal hacia dentro, y del de los Estados con déficits democráticos hacia fuera. En los tiempos de las guerras preventivas esto obliga a ser receloso de la idea rawlsiana de sociedad «bien ordenada».

\section{Pluralismo ambiental}

Hay, no obstante, una segunda razón para ajustar el esquema rawlsiano. La generalidad y universalidad de un requisito político externo -como propone Hailwoodinvita a pensar en un reconocimiento del mismo al nivel de esencias constitucionales. La mayoría de las constituciones aprobadas en los últimos treinta años en sociedades democráticas, como la Constitución española en el art. 45, o convenios internacionales como el de Aarhus sancionan el derecho al medio ambiente sano. Aunque no lo hace la Constitución norteamericana, ni siquiera el Tratado constitucional europeo, una concepción política stricto sensu debería incluirlo, de acuerdo al segundo principio.

Rawls podría aducir que Estados Unidos es su sociedad liberal de referencia, y que aunque en ella el derecho a un medio ambiente saludable no es un derecho fundamental, tiene una segunda oportunidad en la fase legislativa, en el proceso democrático. Rawls incluso se refiere de soslayo a la posibilidad de que políticas ambientales amplias puedan, como otras propuestas sostenidas en ideales comprehensivos, ser apoyados por una mayoría de votantes y por tanto sea la que debe perseguir el Estado ${ }^{21}$. Es decir, la preservación de un espacio natural antes que la del imaginario Manhattan global que el liberal Wissemburg propone ${ }^{22}$ no se sigue de la razón pública, es una opción más a defender sobre bases comprehensivas en la arena política. A pesar de ello, aunque la regla de la mayoría pueda beneficiar a una concepción comprehensiva dada sea la de los defensores de la caza del zorro o la de los defensores del bienestar animal-, el límite externo lo da la razón pública y su ámbito debe quedar a salvo de las doctrinas.

Hay que señalar que «público» se refiere a escenarios y funciones gubernamentales-estatales o casi: actos administrativos, debates parlamentarios, toda actividad electoral y de partido, incluido el voto. Lo «no-público», por el contrario, refiere a lo no gubernamental-estatal, lo que tiene que ver con iglesias, universidades, clubes, etc. Esto es lo que en general se considera la sociedad civil, aunque Rawls evita el término. En este ámbito el ciudadano puede promover acuerdos justos que no sean excesivamente costosos para él y además llevar a cabo acciones privadas como reciclar o reducir el uso del transporte privado, que, en cualquier caso, podrían justificarse desde argumentos comprehensivos y no estarían sujetas a la coacción del Estado aunque podrían ser formalizadas en el proceso político.

Lo público, como ya se ha dicho, está restringido al consenso entrecruzado en su contenido - concepción política de la justicia y valores políticos-y en su método - lo razonable- Esto es objeto de denuncia, por ejemplo, para Thomas McCarthy, para quien lo «no-público», el sistema nervioso de la esfera pública política y termómetro de la democracia, no puede desafiar la interpretación dominante de los temas fundamentales según el consenso de salida. Los fundamentos de la justicia y la política en una sociedad bien ordenada excluyen así — según McCarthy - razones como las que han sostenido los movimientos sociales emancipadores ${ }^{23}$. A saber, cuando los ciudadanos apoyan agendas políticas no pueden apelar a las mismas razones que usan en el foro de la opinión pública. Así, el suelo común 
de la justificación pública, no está en manos de los propios participantes, está definido a priori en el lenguaje liberal de los derechos de ciudadanos libres e iguales, al que los actores deben ceñirse.

El movimiento por la justicia ambiental en Estados Unidos puede servir para poner a prueba este esquema. Desde principios de los años ochenta, y tras la estela de los movimientos por los derechos civiles, emergió como crítica de la «distribución desproporcionada de riesgos ambientales» que, como es previsible y como el movimiento demostró estadísticamente, caen sobre poblaciones estigmatizadas por su raza, etnia, y/o estatus socioeconómico. Tras años de lucha su influencia creció y supuso numerosos cambios legales, incluso la aprobación de una directiva federal en 1994 por el gobierno Clinton, en un proceso en que las reivindicaciones del movimiento se acomodaron a los argumentos de la cultura política dominante. En un principio, el ideario del movimiento mostró un marcado carácter etnicista y un perfil comprehensivo: «Nosotros la gente de color, reunidos [...], establecemos por la presente nuestra interdependencia espiritual con la sacralidad de nuestra Madre Tierra $[. ..]{ }^{24}$. A día de hoy, la reivindicación descansa mayormente en argumentos sobre asignación de recursos, salud pública, seguridad de los trabajadores y participación ciudadana, en particular para poblaciones minoritarias -como los nativos-y de bajo ingreso.

Este ejemplo parece ratificar la fuerza del marco que discutimos: Un actor social restringe su doctrina comprehensiva a lo no-público, traduce su situación a un discurso neutral y logra satisfacer sus aspiraciones integrándose en una pluralidad de actores y posiciones diversas, coincidentes en un consenso originario. De todas formas, como señala Jesús Rodríguez, este cierto aire de familia entre el pluralismo sociológico y el pluralismo razonable rawlsiano no debería ocultar ciertas limita- ciones de enfoque ${ }^{25}$. Rodríguez piensa sobre todo en la existencia de cortapisas a la aparición y formulación de ciertas ideas $y$ posiciones en el entramado institucional del consenso que, en nuestro caso, y por poner un ejemplo, obligan a preguntarse por qué el régimen de partidos norteamericano bloquea la viabilidad de un partido verde, o más aún, por qué los grupos que defienden formas de justicia ambiental global —como los célebres observatorios, o Watch- son más conocidos fuera del país que dentro de él.

Sin embargo, hay dos motivos añadidos que escapan también al esquema. En particular, nuestro caso fue también una lucha social por el reconocimiento, que implicó atrevidas y constantes acciones de protesta y enfrentamientos. No fue una simple deliberación y la fuerza de los argumentos lo que permitió la «aparición» del movimiento. De otro lado, la propia doctrina del movimiento se transformó. Discursivamente, el ideario comprehensivo no fue arrinconado a lo no-público, básicamente mutó en la propia interacción con interlocutores como la administración o los científicos. Éste es un hecho que se repite a distintas escalas, y que se está dando también entre los actores ecológicos globales, que optan cada vez más por nociones seculares de la naturaleza - como la de la huella ecológica- y de los derechos en su lucha global. A resultas de este dinamismo conflictivo la legislación internacional ha incorporado cada vez más y mejores normativas ambientales, aunque, como le ocurre también al movimiento por la justicia ambiental, las leyes no siempre se cumplen.

No es menos relevante que las razones aducidas por estos actores suelen ser las mismas en el ámbito público y no público, y que rara vez suponen una doctrina que prescriba «todas las cuestiones desde la conducta individual a las relaciones personales o la organización de la sociedad como un todo». Sólo traicionando los tér- 
minos se las podría considerar comprehensivas. Quizás Rawls vaya muy lejos al identificar comprehensivo con metafísico y doctrina con concepción moral. Es así como llega a equiparar las concepciones filosóficas y religiosas y pasa por alto la existencia de ideologías no doctrinarias o de filosofías no metafísicas. No es el único, sin duda. El propio Tratado constitucional europeo cae en la confusión entre convicciones religiosas, filosóficas y sus respectivas asociaciones (art. I-52). Sin embargo, la mayoría de tradiciones filosóficas contemporáneas y en particular las teorías políticas difícilmente pueden ser consideradas monolitos comprehensivos o metafísicos, a pesar de tener concepciones particulares de la sociedad y la naturaleza humana. El ecologismo soporta sus concepciones en las ciencias de la naturaleza; como muchas otras ideologías, no prescribe fórmulas totalizadoras de la vida o la historia; además, se rehace y actualiza en un proceso público de aprendizaje.

\section{Conclusiones}

Según hemos visto, cuanto más nouménica es la concepción de las partes en la posición original más incluyente resulta a nuestros efectos. La imparcialidad lleva a la distribución equitativa de los recursos naturales según el principio de diferencia, a la protección del capital natural crítico según el principio de ahorro, y a la del irreversible según el principio de igualdad de oportunidades. Si esto fuese concebible también en lo intrageneracional, podríamos hablar de un tratamiento realmente amplio de la cuestión ambiental, a pesar del déficit respecto a los intereses de seres sensibles no humanos. Aparentemente, la teoría de la justicia parecería salir beneficiada en comparación a la concepción más práctica de la política del liberalismo. Sin embargo, no hay que olvidar que Rawls giró en esa dirección ante la contundencia de las críticas recibidas por su tratamiento abstracto del sujeto, y esta duda sigue abierta. Una noción «de-situada», «flotante», del mismo no cabe tampoco en la antropología ecológica ${ }^{26}$.

Del mismo modo, cuanto más «independiente» es la concepción política, más sentido tiene incluir entre las esencias constitucionales el derecho a un medio ambiente saludable e incluso más fácilmente podría suavizarse el antropocentrismo. Sin embargo, la concepción se torna necesariamente comprehensiva si las intuiciones morales de ciertos ciudadanos nacionales en su vida diaria tienen lugar en una sociedad aparentemente «westfaliana». No hay que desdeñar un tal esfuerzo de reivindicar la tolerancia y la laicidad del Estado en un momento histórico de gran involución de la cultura política anglosajona. A pesar de ello, el imaginario político del liberalismo ambientalmente razonable no debería anclarse en una ontología propia de la primera modernidad.

\section{NOTAS}

1 Seguimos las siguientes obras y ediciones: John Rawls, A Theory of Iustice, Oxford, Oxford University Press, 1973; El liberalismo político, Barcelona, Crítica, 1996; El derecho de gentes, Barcelona, Paidós, 2001; La justicia como equidad. Una reformulación, Barcelona, Paidós, 2002.

2 Russ Manning, «Environmental Ethics and John Rawls' Theory of Justice», Environmental Ethics, núm. 3, 1981; y desarrollada con mayor detalle por Norman Daniels, Just Health Care, Cambridge, Cambridge University Press, 1994.

${ }_{3}$ Mathis Wackernagel et al., «Tracking the ecological overshoot of the human economy», Proceedings of the NationalAcademyof Sciences, vol.99, núm.4, 2002.

4 Wilfred Beckerman, «Debate: Intergenerational Equity and the Environment», The Journal of Politi- 
cal Economy, vol. 5, núm. 4, 1997; Bjørn Lomborg, El ecologista escéptico, Madrid, Espasa, 2003.

5 Ted Benton, «Ecology, community and justice», en T. Hayward y J. O'Neill, Justice, Property and the Environment, Aldershot, 1999.

- Derek Bell, «How Can Political Liberals be Environmentalists?», Political Studies, vol. 59, núm. 4,2002 , p. 713.

7 Peter Singer, «An Extension of Rawls' Theory of Justice to Environmental Ethics», Environmental Ethics, vol. 10, 1998.

8 Brian Barry, «Sustainability and Intergenerational Justice», en A. Dobson (ed.), Fairness and Futurity: Essays on Sustainability and Justice, Oxford, Oxford University Press, 1999, p. 95.

9 Alberto Saoner, Historia y conceptos de ética y filosofia política, Palma, UIB, 2004, p. 473.

10 Robert Garner, «Animals, Politics and Justice: Rawlsian Liberalism and the Plight of Non-Humans», Environmental Politics, vol. 12, núm. 2, 2003.

$"$ Tratado por el que se establece una Constitución para Europa, Bruselas, 2004.

12 Brian Barry, Teorías de la justicia, Barcelona, Gedisa, 1995.

13 «Sustainability and Intergenerational Justice», op. cit.

14 Ulrich Beck, «La sociedad del riesgo reexaminada: la amenaza terrorista», en J. L. Luján y J. Echeverría (eds.), Gobernar los riesgos. Ciencia y valores en la sociedad del riesgo, Madrid, Biblioteca Nueva, 2004, p. 182.

15 Ver en el monográfico de Ethics (núm. 110, 2000) los artículos de Charles Beitz, «Rawls's Law of Peoples», y de Allen Buchanan, «Rawls's Law of Peoples: Rules for a Vanished Westphalian World»; y en el de Metaphilosophy (vol. 32, 2001), Wein Lenar; «Contractualism and Global Economic Justice», Charles Beitz, «Does Global Inequality Matter?», y Thomas Pogge, «Priorities of Global Justice».
${ }_{16}$ El liberalismo político, op. cit., pp. 280-281.

17 Véase Andrew Dobson, Citizenship and the Environment, Oxford, Oxford University Press, 2003, cap 4.

${ }_{18}$ Simon Hailwood, «Environmental Citizenship as Reasonable Citizenship», en A. Dobson y A. Valencia (eds.), Citizenship, Economy and Environment, Londres, Routledge, 2005.

${ }^{19} \mathrm{El}$ antropocentrismo epistemológico es por supuesto inevitable para el filósofo. No obstante, en otros sentidos, como el que toca Hailwood, la concepción de lo natural como «otro» podría ser parte de una ontología realmente «neutral».

${ }^{20}$ Derecho de gentes, op. cit., p. 136.

21 La justicia como equidad, op, cit, p. 205, n. 26. Esta vía es defendida por Derek Bell en «Liberal Environmental Citizenship», en A. Dobson y A. Valencia (eds.), Citizenship, Economy and Environment, Londres, Routledge, 2005.

${ }^{22}$ Marcel Wissemburg, Green Liberalism. The Free and the Green Society, Londres, UCL, 1998, p. 1.

23 Thomas McCarthy, «Kantian Constructivism and Reconstructivism: Rawls and Habermas in Dialogue», Ethics, núm. 105, 1994, p. 53.

24 «Principios de Justicia ambiental», presentados en Río en la primera Cumbre de la Tierra en 1992; accesible en www.ejrc.cau.edu/princej.html. Véase Henri Acselrad, «Movimiento de justicia ambiental. Estrategia argumentativa y fuerza simbólica», en J. Riechmann (coord.), Ética ecológica, Montevideo, Nordan, 2004.

${ }_{25}$ Jesús Rodríguez Zepeda, La política del consenso. Una lectura crítica de El liberalismo político de John Rawls, Barcelona, Anthropos, 2003, pp. 208-218.

${ }^{26}$ Derek Bell, «Liberal Environmental Citizenship», op. cit. 